\title{
COVID-19 Neurologic Complication with CNS Vasculitis-Like Pattern
}

\author{
(D) R. Hanafi, (DP.-A. Roger, (D)B. Perin, (D). Kuchcinski, (D) N. Deleval, (D). Dallery, (DD. Michel, (D) L. Hacein-Bey, (D).-P. Pruvo, \\ (iD) Outteryck, and (D).-M. Constans
}

\begin{abstract}
SUMMARY: Coronavirus disease 2019 (COVID-19) is a viral infection caused by the Severe Acute Respiratory Syndrome coronavirus 2 (SARS-CoV-2), which spreads rapidly from person to person and manifests in most symptomatic patients as a respiratory illness, similar to prior SARS viruses. Neurologic manifestations of COVID-19 are uncommon; those so far reported include encephalopathy, stroke from large-vessel occlusion, and polyneuropathy. We report a unique neurologic complication of COVID-19 in a patient who had extensive cerebral small-vessel ischemic lesions resembling cerebral vasculitis in a characteristic combined imaging pattern of ischemia, hemorrhage, and punctuate postcontrast enhancement. Also, a characteristic lower extremity skin rash was present in our patient. Our observation lends support to the increasingly suspected mechanism of "endotheliitis" associated with this novel coronavirus.
\end{abstract}

ABBREVIATIONS: ACE2 = angiotensin converting enzyme 2; COVID-19 = coronavirus disease 2019; SARS-CoV-2 = Severe Acute Respiratory Syndrome coronavirus 2

C oronavirus disease 2019 (COVID-19) has now spread to the whole world following an outbreak in China in late 2019. ${ }^{1}$ The virus is so highly contagious that the World Health Organization has declared COVID-19 a pandemic, with close to 3.5 million confirmed cases and 250,000 fatalities worldwide at the time of this report (May 1, 2020). ${ }^{1,2}$ Similar to other coronaviruses, the Severe Acute Respiratory Syndrome coronavirus 2 (SARS-CoV-2) virus primarily targets the respiratory system. In symptomatic patients, the most common symptoms are fever, fatigue, cough, headache, and shortness of breath. Severely symptomatic patients may present with pneumonia, acute respiratory distress syndrome, acute cardiac dysfunction from myocarditis, and multiorgan failure. ${ }^{3-5}$ Several mild neurologic manifestations of COVID-19 have now been reported, which include hyposmia or anosmia. ${ }^{6-8}$ More severe neurologic complications have also been recently

Received April 23, 2020; accepted after revision May 5.

From the Department of Neuroradiology (R.H., G.K., J.-P.P., O.O.), University Hospital of Lille, Hôpital Roger Salengro, Lille, France; Departments of Interventional Radiology (R.H.), Cardiothoracic, Vascular and Respiratory Intensive Care (P.-A.R.), Neurology and Neurophysiology (B.P.), and Neuroradiology (N.D., F.D., D.M., J.-M.C.), University Hospital of Amiens, Amiens, France; and Departments of Neuroradiology and Radiology (L.H.-B.), University of California Davis School of Medicine, Sacramento, California.

Please address correspondence to Hanafi Riyad, MD, University Hospital of Lille Department of Neuroradiology, Hôpital Roger Salengro, Avenue du Professeur, Emile Laine, 59037, Lille, France; e-mail: riyad.hanafi@chru-lille.fr

- Indicates open access to non-subscribers at www.ajnr.org

http://dx.doi.org/10.3174/ajnr.A6651 reported, which may possibly be associated with COVID-19, including acute hemorrhagic necrotizing encephalopathy, ${ }^{9}$ acute transverse myelitis and Guillain Barré syndrome, ${ }^{10}$ and meningitis. ${ }^{11}$

We report herein a unique neurologic complication of COVID-19 with extensive ischemic lesions resembling CNS vasculitis.

\section{Case Report}

A 65-year-old man presented to the emergency department with a 5-day history of fatigue, fever, and cough. Initial blood work showed an inflammatory syndrome with an elevated Creactive protein $(60 \mathrm{mg} / \mathrm{L}$ ), bicytopenia (normocytic anemia and thrombocytopenia), and lymphopenia. The patient was admitted to the medical ward for further evaluation. Noncontrast chest CT showed ground-glass opacities characteristic of COVID-19 infection. The diagnosis was confirmed by reverse transcription polymerase chain reaction detection of SARS-CoV-2 from a nasopharyngeal swab.

The following day, the patient had a high fever and chills. A lower extremity skin rash was noted. Severe hypoxemia (56 mm $\mathrm{Hg}$ ) and low oxygen saturation (90.6\%) prompted oxygen therapy with a high-concentration mask $(15 \mathrm{~L} / \mathrm{min})$ and antibiotic therapy (spiramycin, amoxicillin, and clavulanic acid). Because oxygen saturation continued to drop to $88 \%$, with worsening of skin rash and tachypnea, the patient was admitted to the pulmonary intensive care unit. 


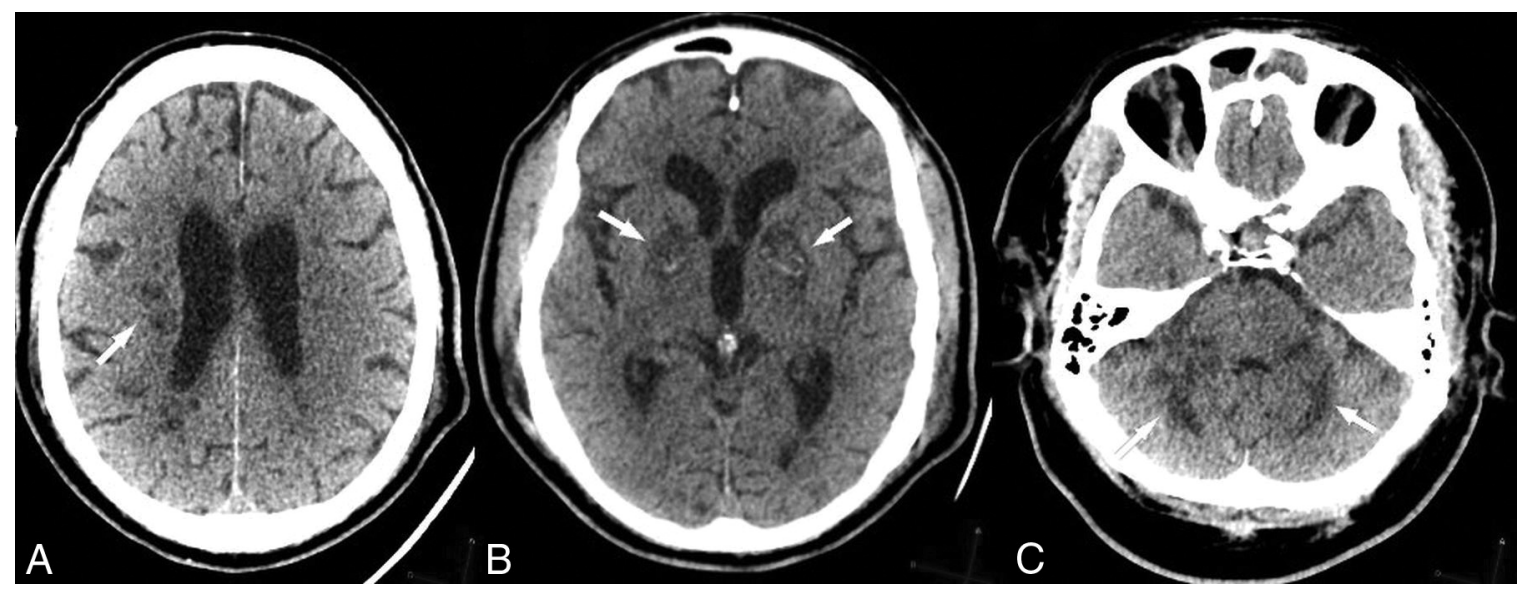

FIG 1. Noncontrast brain CT of presumptive COVID-associated small-vessel injury. Note deep white matter $(A)$, basal ganglia ( $B)$, and cerebellar (C) hypodensities (arrows). Bilateral globus pallidus hemorrhage is also present (B, arrows).

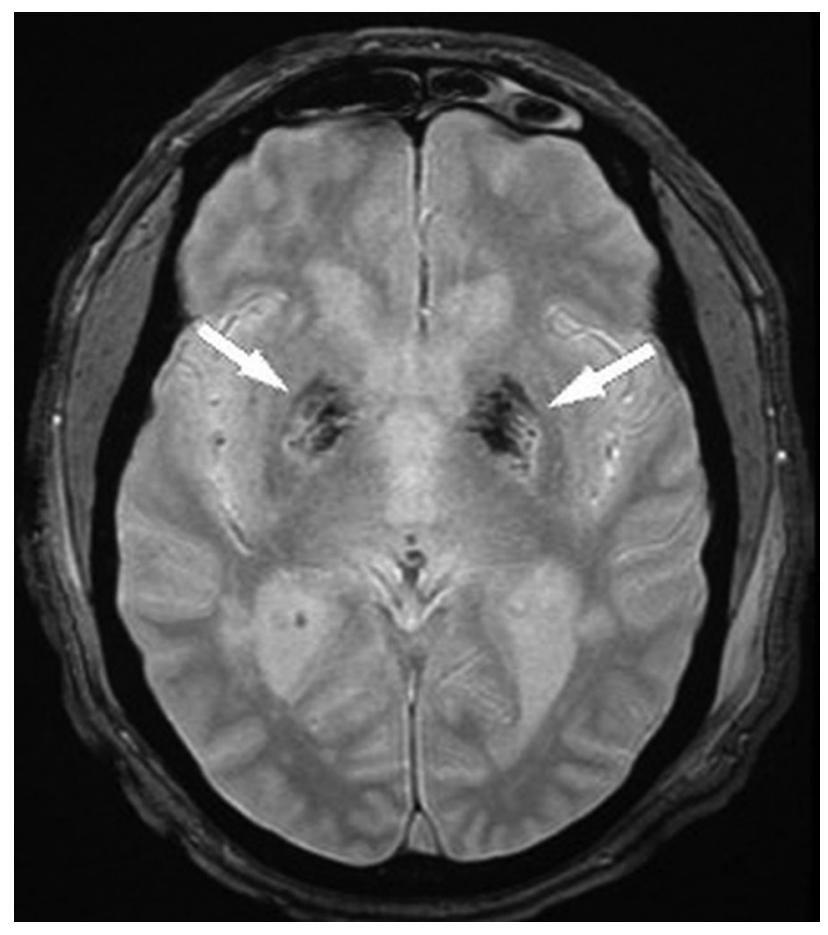

FIG 2. $T 2^{*}$-weighted MR imaging demonstrates bilateral globus pallidus susceptibility, consistent with microhemorrhage (arrows).

Rapid stabilization of pulmonary function was obtained with oxygen and care in the intensive care unit; however, the patient remained drowsy and unarousable despite discontinuation of sedation. CT and MR imaging of the brain were performed to look for possible neurologic complications such as hypoxic-ischemic injuries or encephalitis. CT showed multiple white matter, basal ganglia, and cerebellar hypodensities and bilateral globus pallidus hyperdensities (Fig 1), suggestive of hemorrhage confirmed on $\mathrm{T} 2{ }^{\star}$-weighted MR imaging (Fig 2).

Brain MR imaging showed extensive ischemic lesions with restricted diffusion (Fig 3), involving the centrum semiovale, corpus callosum, basal ganglia, and cerebellum

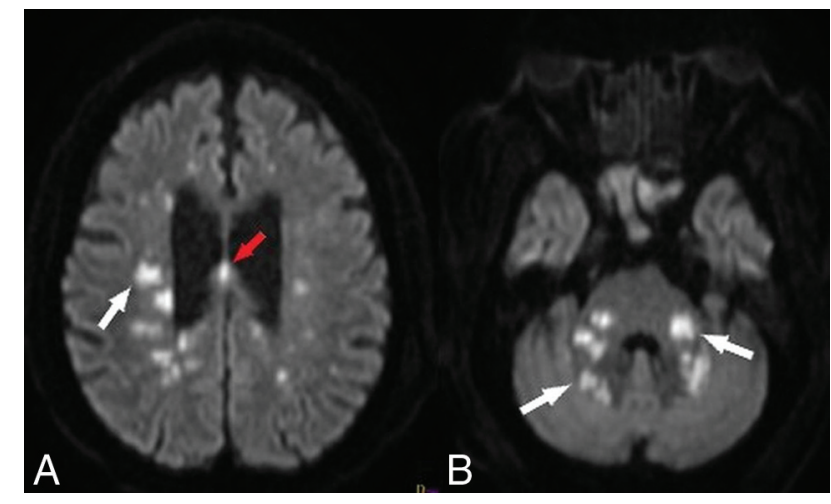

FIG 3. Diffuse deep white matter ischemic injuries. DWI shows numerous focal ischemic lesions within the hemispheric deep white matter ( $A$, white arrow), the corpus callosum ( $A$, red arrow), the basal ganglia, the middle cerebellar peduncles, and the cerebellar hemispheres ( $B$, white arrows).

(Fig 4), with patchy/punctuate enhancement (Fig 5). Coronal 3D reconstruction MRA of supra-aortic arteries showed no detectable abnormality of large intra- or extracranial vessels (Fig 6).

\section{DISCUSSION}

Neurologic complications are definitely associated with COVID19 , though the mechanism of neurologic injury remains speculative. Encephalopathy, ischemic stroke from large-vessel occlusion, ${ }^{7-9,12}$ Guillain-Barré syndrome, ${ }^{10}$ and reversible cranial nerve injuries (Miller Fisher syndrome) ${ }^{13}$ have all been reported with no evidence thus far that the SARS-CoV-2 can cross the bloodbrain barrier. $^{12,13}$

In our patient, hypoxic-ischemic injury was considered an unlikely mechanism of injury because the patient had remained responsive throughout the period of low oxygen saturation, and only deteriorated several hours after successful stabilization of oxygen saturation; in addition, the patient did not have cardiac arrest. Also, imaging studies showed sparing of the striatum and cortical structures throughout. 


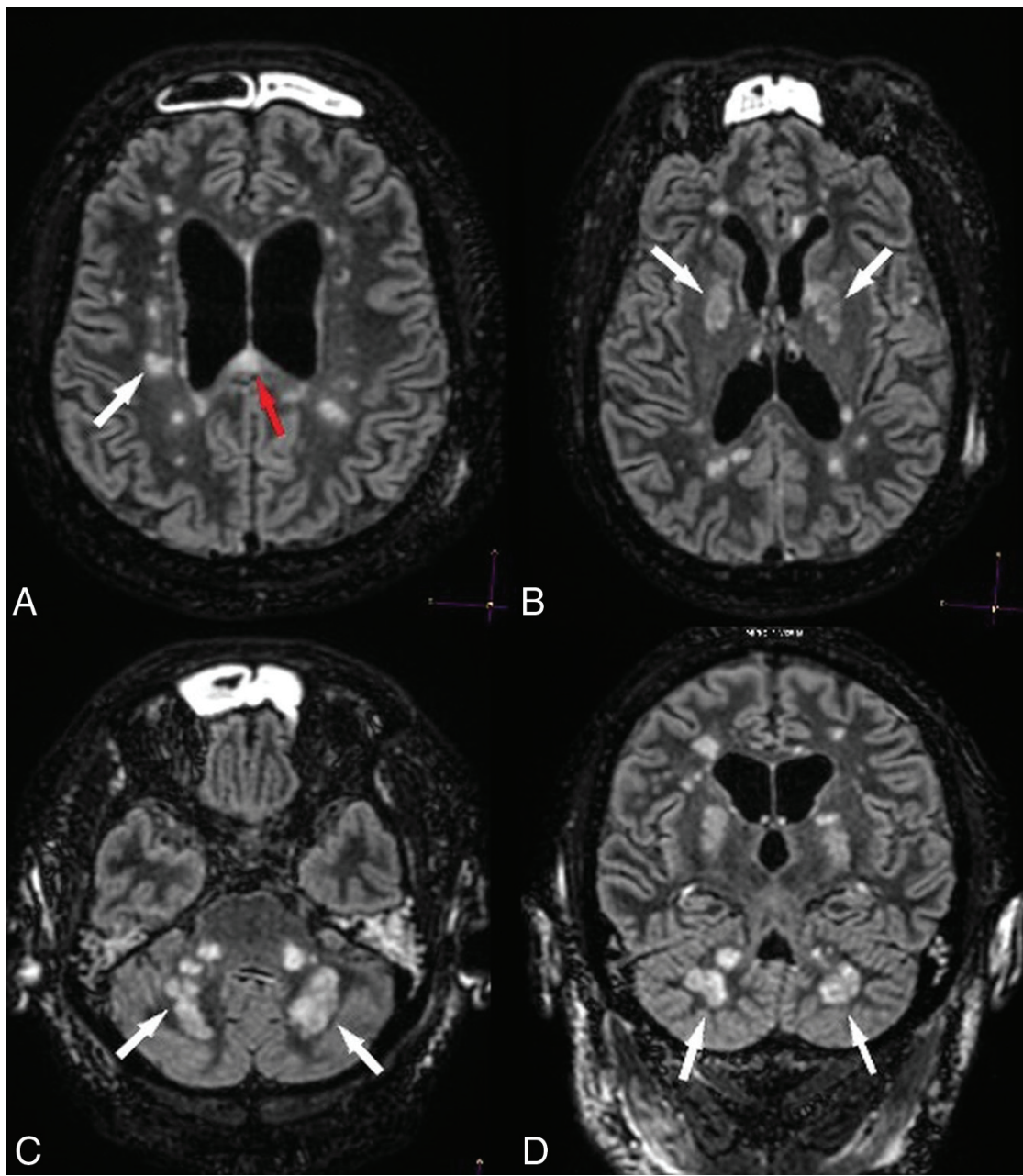

FIG 4. Diffuse ischemic lesions on FLAIR imaging. Axial $(A-C)$ and coronal $(D)$ FLAIR images show hyperintense ischemic lesions within the periventricular white matter, basal ganglia, cerebellar peduncles (white arrows), and the corpus callosum ( $A$, red arrow).

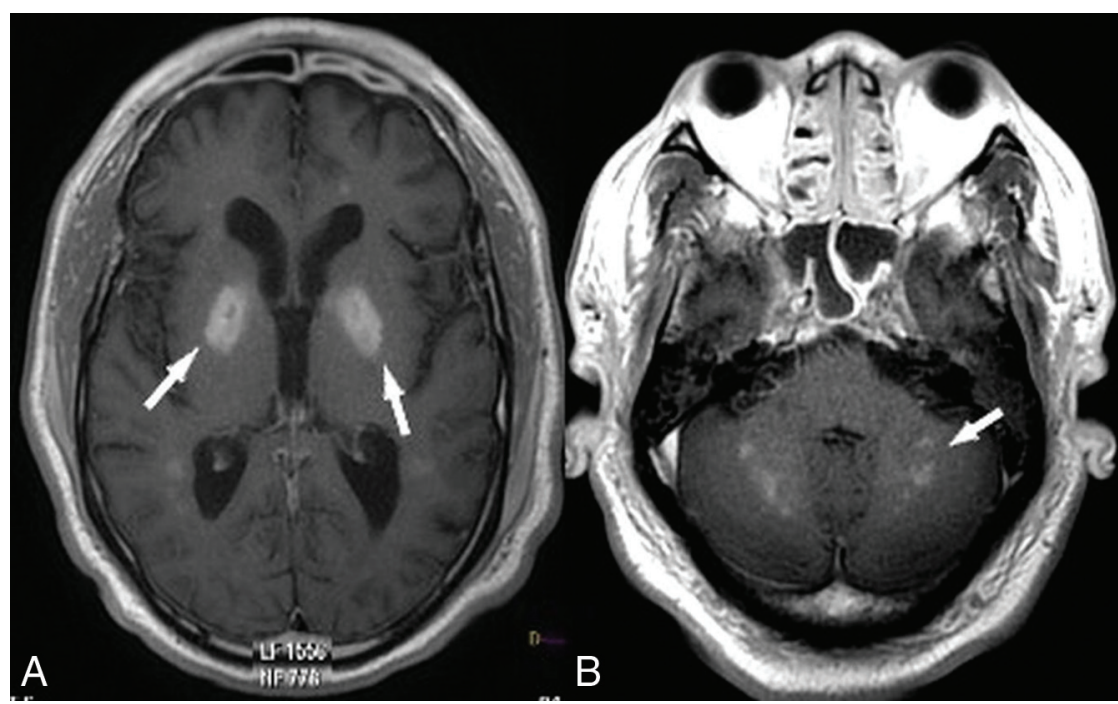

FIG 5. Patchy/punctate postcontrast enhancement pattern with consistent small vessel involvement. Postcontrast TI MR imaging shows intense patchy enhancement of all lesions, in particular the globus pallidus bilaterally ( $A$, white arrows), with a punctuate pattern in the middle cerebellar peduncles and cerebellar hemispheres $(B$, arrow).
Similarly, a pro-thrombotic state was not considered a likely causative factor because thorough coagulation panel findings (including the antiphospholipid antigen) were normal.

Neuroimaging findings in our patient suggest the possibility of injury to the small intracranial vasculature in the distribution of distal perforating arteries. The association of ischemic and hemorrhagic lesions to the "patchy/punctate" enhancement pattern is highly suggestive of vasculitis. ${ }^{14}$ The punctate enhancement pattern has been reported to be characteristic of disease processes that progress from endoluminal (angiocentric lymphoma), vessel wall (vasculitis), or perivascular (progressive multifocal leukoencephalopathy) cellular proliferation. ${ }^{15}$

SARS-CoV-2 infects the host through its $\mathrm{CoV}$ spike glycoprotein, which binds to the angiotensin converting enzyme 2 (ACE2) receptor, which is expressed in the lungs, heart, and kidney (the most frequenty targeted organs in COVID-19), but also endothelial cells. ${ }^{16}$ Endothelial cell involvement with COVID-19 has recently been demonstrated across vascular beds. ${ }^{17}$ The expression of the ACE2 receptor in neurons and cerebral endothelial cells indicates a high level of invasiveness for the SARSCoV-2 in comparison with other coronaviruses (SARS and Middle East Respiratory Syndrome). ${ }^{18}$ Such an endothelial mechanism of injury (endotheliitis) has been convincingly demonstrated in severe cases of cardiac injury in humans. ${ }^{19}$ Histologic evidence of COVID-19-induced vasculitis has also been reported in several other organs including the lung, liver, kidney, or skin. ${ }^{20,21}$ The concomitance of a characteristic skin rash with a "mottled" appearance and such a pattern of CNS lesions in our patient would lend support to a mechanism of virus-related endothelial injury.

\section{CONCLUSIONS}

COVID-19-related neurologic complications remain poorly understood. We report a patient whose clinical presentation and neuroimaging findings 


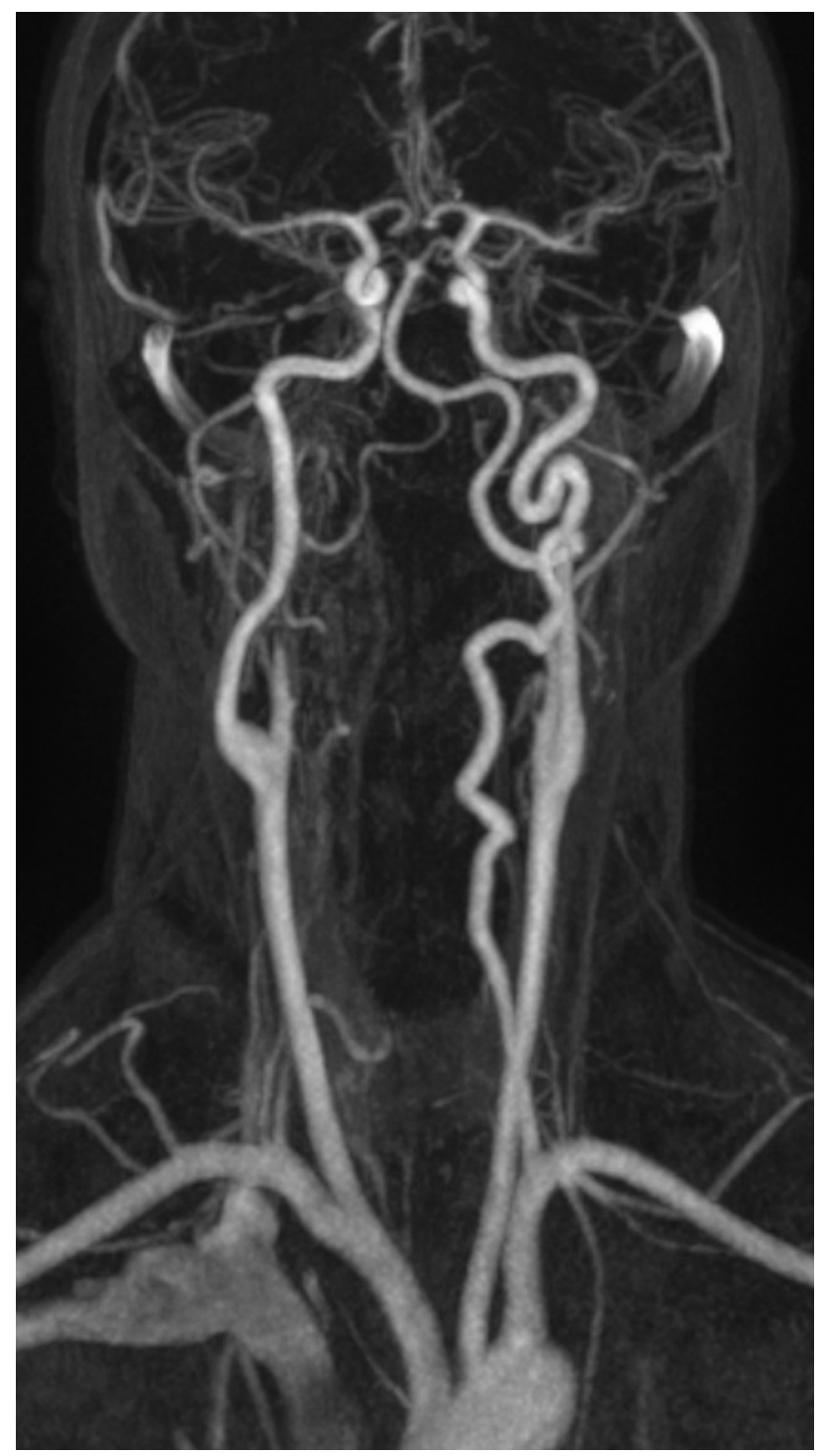

FIG 6. Coronal 3D reconstruction MRA of the supra-aortic arteries shows no detectable abnormality of large intra- or extracranial vessels.

are supportive of a mechanism of SARS-CoV-2-induced vasculitis/endotheliitis.

\section{ACKNOWLEDGMENTS}

The authors wish to acknowledge Fanny Ducourneau, radiologic technologist, and Gilles Boulu, radiologist, who kindly agreed to perform the MR imaging study in our patient.

\section{REFERENCES}

1. World Health Organization. Coronavirus disease 2019. 2020 April 30. https://www.who.int/emergencies/diseases/novel-coronavirus2019. Accessed April 30, 2020
2. COVID-19 CORONAVIRUS PANDEMIC. May 20 2020. https:// www.worldometers.info/coronavirus. Accessed April 30, 2020

3. 2019-20 Coronavirus Pandemic. Public Health Emergency. Coronavirus https://www.who.int/emergencies/diseases/novelcoronavirus-2019. Accessed April 30, 2020

4. US Centers for Disease Control and Prevention. Symptoms of Novel Coronavirus (2019-nCoV). February 10, 2020. https://www.cdc.gov/ coronavirus/2019-ncov/symptoms-testing/symptoms.html. Accessed April 30, 2020

5. Huang C, Wang Y, Li X, et al. Clinical features of patients infected with 2019 novel coronavirus in Wuhan, China. Lancet 2020;395:497506 CrossRef Medline

6. Clinical characteristics of $\mathbf{1 1 3}$ deceased patients with coronavirus disease 2019: retrospective study. BMJ 2020;368:m1295 CrossRef Medline

7. Mao L, Jin H, Wang M, et al. Neurologic manifestations of hospitalized patients with coronavirus disease 2019 in Wuhan, China. JAMA Neurol 2020 April 10. [Epub ahead of print] CrossRef Medline

8. Avindra N. Neurologic complications of coronavirus infections. Neurology 2020;94:809-10 CrossRef Medline

9. Poyiadji N, Shahin G, Noujaim D, et al. COVID-19-associated acute hemorrhagic necrotizing encephalopathy: CT and MRI features. Radiology 2020 Mar 31. [Epub ahead of print] CrossRef Medline

10. Zhao H, Shen D, Zhou H, et al. Guillain-Barré syndrome associated with SARS-CoV-2 infection: causality or coincidence. Lancet Neurol 2020;19:383-84 CrossRef Medline

11. Moriguchi T, Harii N, Goto J, et al. A first case of meningitis/encephalitis associated with SARS-coronavirus-2. Int J Infect Dis 2020;94:55-58 CrossRef Medline

12. Filatov A, Sharma P, Hindi F, et al. Neurological complications of coronavirus disease (COVID-19): encephalopathy. Cureus 2020;12: e7352 CrossRef Medline

13. Gutiérrez-Ortiz C, Méndez A, Rodrigo-Rey S, et al. Miller Fisher syndrome and polyneuritis cranialis in COVID-19. Neurology 2020 Apr 17. [Epub ahead of print] CrossRef Medline

14. Gupta RK. Small vessel vasculitis-optimism and challenges in imaging diagnosis. Neurol India 2017;65:1219-20 CrossRef Medline

15. Hodel J, Darchis C, Outteryck O, et al. Punctate pattern: a promising imaging marker for the diagnosis of natalizumab-associated PML. Neurology 2016;86:1516-23 CrossRef Medline

16. Monteil V, Kwon H, Prado P, et al. Inhibition of SARS-CoV-2 infections in engineered human tissues using clinical-grade soluble human ACE2. Cell 2020;181:905-913.e7 CrossRef Medline

17. Varga Z, Flammer AJ, Steiger P, et al. Endothelial cell infection and endotheliitis in COVID-19. Lancet 2020;395:1417-18 CrossRef Medline

18. Natoli S, Oliveira V, Calabresi P, et al. Does SARS-Cov-2 invade the brain? Translational lessons from animal models. Eur J Neurol 2020 Apr 25. [Epub ahead of print] CrossRef Medline

19. Chen L, Li X, Chen M, et al. The ACE2 expression in human heart indicates new potential mechanism of heart injury among patients infected with SARS-CoV-2. Cardiovasc Res 2020;116:1097-1100 CrossRef Medline

20. Xu Z, Shi L, Wang Y, et al. Pathological findings of COVID-19 associated with acute respiratory distress syndrome. Lancet Respir Med 2020;8:420-22 CrossRef Medline

21. Yao XH, Li TY, He ZC, et al. A pathological report of three COVID-19 cases by minimally invasive autopsies [in Chinese]. Zhonghua Bing Li Xue Za Zhi 2020;49:411-17 CrossRef Medline 